\title{
Otra ciencia económica
}

\author{
Another economic science
}

\author{
DANIEL INNERARITY
}

UNIVERSIDAD DE ZARAGOZA

\section{Resumen}

El autor hace una crítica a la pretensión de la ciencia económica de constituirse como un saber exacto e hiperespecializado al considerar que esta pretensión se ha traducido en una pérdida de la capacidad que es necesaria para comprender la complejidad social de las realidades económicas. Seducida por el objetivo de la exactitud, la economía parece haber olvidado su carácter de construcción social. Además, la economía ha olvidado que es una más entre las ciencias sociales y el largo periodo en el que se ha separado de ellas reivindicando su plena autonomía no ha sido satisfactorio ni para ella ni para el resto de las ciencias sociales. Según el autor la crítica al capitalismo contemporáneo, si quiere ser más radical que moralizante, debe dirigirse a combatir el supuesto realismo de la ciencia económica dominante.

Palabras clave: crisis económica, ciencia económica, mercado, entorno social.

\begin{abstract}
The author criticizes the pretension of economic sciences of being an exact science and its tendency to specialization. The consequences of those pretensions are a loss of its capacity to understand the social complexity of the economic realities. The economy, seduced by its aim of exactitude, seems to forget that it is a social construction. Moreover, economy seems to forget that it is just a social science, and for a long period of time economy evolved as a separated and autonomous science; that time was not good neither for economic science neither for social sciences in general. According to the author, if we want to build a more radical and not only moralizing critique to contemporary capitalism, we must criticize the hypothetical realism of the economic science.
\end{abstract}

Keywords: economic crisis, economic science, market, social framework.

La crisis económica ha afectado también a los instrumentos que deberían describirla, el marco intelectual y conceptual que sostiene nuestra comprensión de las realidades económicas. La pérdida de confianza en los mecanismos financieros ha abierto la era de la desconfianza más general hacia la ciencia económica dominante, de la que se sospecha estar maniatada por una concepción demasiado estrecha de lo humano, fundada únicamente en la maximización de beneficios y de acuerdo con un modelo mecanicista simple, muy poco sensible a las dimensiones sistémicas y sociales de la realidad económica. ¿No será que la crisis, que expresa una fatal des- 
vinculación entre lo económico y lo social, ha sido precedida por una ciencia económica que se había desentendido sistemáticamente de esa interacción? Nadie puede cuestionar el derecho de cualquier científico a elaborar modelos y teorías abstractas, pero cuando se trata de recomendar decisiones colectivas las disquisiciones teóricas se enfrentan a una legitimidad pública en el orden de sus efectos sociales.

Muchos analistas han señalado que la reciente crisis financiera tiene su origen en la evolución de la ciencia económica desde 1970. Las causas que se citan habitualmente para explicar la crisis actual son todas ellas ciertas, pero no deberíamos dejar de mencionar causas epistemológicas o científicas. Las teorías no son siempre inofensivas; algunas veces lo que se piensa tiene consecuencias sobre lo que ocurre. Ha habido, por supuesto, codicia ilimitada, efectos de contagio y fracaso de la regulación, pero todo esto no habría sido posible en última instancia si no hubiera estado preparado por un determinado pensamiento económico. La economía ha construido en estos últimos años una representación muy abstracta del mercado como mecanismo casi perfecto de autorregulación. Se han establecido como verdades incontestables la racionalidad de los agentes, la eficiencia de los mercados y un enfoque de los asuntos económicos completamente abstraído del entorno social.

La crisis nos plantea a todos diversos ejercicios de responsabilidad. A los economistas concretamente les ofrece la posibilidad de dirigir una mirada sin complacencia sobre su profesión, teniendo en cuenta que algunas de sus principales perplejidades se deben a la inercia de una construcción epistemológica que estructura poderosamente su práctica, especialmente cuando ha sucumbido a la tentación de obtener un estatuto científico que le garantizara especialización y exactitud.

Podríamos sintetizar esta situación, desde un punto de vista epistemológico, afirmando que la pretensión de la ciencia económica de constituirse como un saber exacto e hiperespecializado se ha traducido en una pérdida de la capacidad que es necesaria para comprender la complejidad social de las realidades económicas. La economía ha perdido, junto con su carácter de ciencia social, moral y política, su capacidad crítica. La matematización de la economía confiere una precisión falaz a un campo que está invadido por premisas discutibles, modelos demasiados simplificados y tomas de partido ideológicas.

La infancia de la economía como disciplina está marcada por la ambición de parecerse lo más posible a una ciencia. En la época en la que se constituye el saber económico como tal -finales del siglo XVIII y principios del XIX- la ciencia dominante era la física. Parecerse a la física, ser algo así como la física de las realidades económicas, suponía entender que la objetividad en las predicciones económicas exigía despojarse de toda dimensión subjetiva, de esos aspectos antropológicos y sociales que le impedían realizar juicios exactos. La historia de la economía como ciencia objetiva es la construcción de un edificio del que son excluidos todos los elementos que podrían cuestionar su estatuto de ciencia exacta. La economía política se 
convirtió en análisis matemático primero y terminó siendo matemática económica, econometría, una pura técnica de análisis de datos que se podría aplicar a cualquier cosa y a cualquier sociedad. Mientras que hasta los años setenta la economía financiera pertenecía al campo de la teoría económica, ahora está fundamentalmente en manos de estadísticos; la disciplina se ha automatizado hasta el punto de casi no tener relaciones con la macroeconomía financiera tradicional. En cierto sentido la crisis actual es la crisis de la división del trabajo entre los economistas.

Seducida por el objetivo de la exactitud, la economía parece haber olvidado su carácter de construcción social. Los mercados no son curvas de oferta que se encuentran en el papel con curvas de demanda, sino construcciones sociales e históricas, instituciones humanas, redes sociales y lugares de poder. Los precios son estados de opinión, disposiciones psicológicas, convenciones sociales. Los valores económicos no tienen la consistencia intrínsecamente objetiva que le ha querido atribuir la teoría económica, como se pone de manifiesto en la caída que experimentan cuando baja la confianza social. Incluso los modelos con los que tratamos de entender los comportamientos económicos son construcciones sociales. El observador o el teórico ejercen un efecto poderoso sobre la realidad que estudia. La economía no puede presumir de exactitud si no es capaz de medir el impacto de sus propias teorías en el objeto estudiado. Nadie ha modelizado, por ejemplo, la manera en que los mismos modelos pueden ser utilizados para dar una falsa sensación de seguridad al sector financiero.

Al olvidar su dimensión social, la abstracción económica se convierte en una verdadera distracción. El afán de exactitud da lugar a una enorme inexactitud social. Esta es la razón que explica el hecho de que la ciencia económica así ejercida formalice mal los aspectos sociales y políticos de una economía de mercado. La eficacia de la división del trabajo en la investigación económica se traduce en pérdida de inteligibilidad de las interdependencias que actúan en todo proceso económico, que es, no deberíamos olvidarlo, un acontecimiento social. Aquí encontramos una primera contradicción que merece ser examinada críticamente. La representación que la economía tiene de sí misma la imagina como una ciencia dura y especializada, lo cual no es compatible con el mantenimiento de su vieja pretensión de mantener un discurso general sobre el orden social, el gobierno de los seres humanos y el destino de las naciones. ¿O es que la exactitud que proporciona la especialización no se paga con algún precio?

El precio no podía ser algo muy diferente del que tiene que pagar toda atención excesiva: la pérdida de visión de conjunto y de su capacidad de gestionar lo que, por su propia naturaleza, se presta mal a encajar en un modelo de exactitud matemática. Los economistas han obtenido la precisión de sus modelos a costa de la verosimilitud de sus previsiones, lo que no sería especialmente grave si no hubieran tratado de convencernos de que la exactitud conquistada hacía innecesario atender a las 
variables menos precisas. El fracaso de los economistas a la hora de anticiparse a la crisis se explica por la especialización y fragmentación de las diversas especialidades, más concretamente, por la ilusión de calculabilidad que esta especialización provocaba. De ahí la curiosa paradoja de que los mejores expertos hayan sido incapaces de detectar una burbuja mientras que, como señalaba un economista americano, todos los taxistas de Miami podían describir a sus clientes con gran exactitud las características de la burbuja inmobiliaria que se empezó a formar a partir de mediados de los años 2000. La economía se encuentra así hoy en una situación paradójica: cuando parece que está en las mejores condiciones de explicar los fenómenos económicos y sociales, se encuentra desamparada y perpleja en medio de una crisis financiera que no ha sido capaz de prever.

El mito de la exactitud comienza por una extrapolación injustificada. En el ámbito microeconómico es donde la teoría económica resulta más verificable empíricamente. Ahora bien, su transposición a espacios económicos más complejos o a la economía global tiene enormes limitaciones. Hay toda una serie de elementos no lineales y reacciones imprevistas que entran en juego a nivel macroeconómico y que las teorías microeconómicas no pueden anticipar. Estos límites de los modelos que quieren extrapolarse a los procesos globales se deben fundamentalmente a que no conocemos bien las leyes de probabilidad para los acontecimientos extremos que son poco frecuentes; la economía es incapaz, por ejemplo, de explicar cómo la cobertura óptima de un riesgo a nivel microeconómico puede desembocar en una crisis sistémica. La teoría neoclásica disimula la inmensidad de las situaciones mal comprendidas o inestables. Algo que ya es difícil de explicar para cualquiera, resulta incomprensible para los modelos reduccionistas: cómo es posible que la adición de comportamientos individuales -que eran racionales en el sentido de la teoría económica- haya podido conducir a resultados masivamente irracionales.

Contra esta idea simplista de la exactitud habla también el hecho de que las normas contables han salido de su neutralidad fotográfica en el curso de estos últimos años. Hace tiempo que no sabemos muy bien qué miden exactamente nuestros modelos de medición exacta. Desde el caso Enron, conocemos mejor los límites de unos principios contables que se han quedado en una visión del ciclo económica salida de la revolución industrial.

Paralelamente se han ido poniendo en cuestión nuestros indicadores para la medición económica. Cada vez somos más conscientes de que las mediciones económicas no son actos neutros sino que implican una serie de preferencias. Se impone una lectura social de los datos económicos para que los indicadores de crecimiento no enmascaren otras preguntas acerca de su distribución en la sociedad.

En torno a esta cuestión gira todo el debate sobre los nuevos indicadores de riqueza. El hecho de que valoremos la calidad del medio ambiente, la seguridad, 
el dinamismo cultural o el sentimiento gratificante de vivir en una sociedad justa pone de manifiesto que nuestro bienestar subjetivo depende de bienes que no están exactamente dentro del mercado, de recursos, productos o servicios cuyo valor de uso no puede ser correctamente reflejado por el valor de cambio. Esta renovación conceptual ha sido el objetivo de la llamada «comisión Stiglitz» sobre el desarrollo económico y el progreso social (con la colaboración de Sen y Fitoussi). Al proponer una modificación del modelo de cálculo del PIB, preguntándose cómo dar cuenta del bienestar o cómo tratar las cuestiones medioambientales a través de los datos estadísticos, se trataba de orientar la economía hacia una medida del bienestar que sobrepasa el estricto marco mercantil y el dogma del crecimiento. Este será un objetivo que deberá ocuparnos más allá de la ocasional «salida de la crisis» o el discurso ritual sobre «otro modelo económico»: medir mejor la riqueza sin focalizarse en una medida por relación a la cual los extremos serían cantidades insignificantes.

Las teorías económicas de estricta observancia tienden a ignorar a las otras ciencias sociales o a absorberlas como aspectos de sus propias construcciones. La ciencia económica ha intentado poner entre paréntesis la naturaleza profundamente subjetiva de los comportamientos económicos con el objetivo de asegurar sus pretensiones de ciencia exacta y favorecer el desarrollo de su matematización. Debemos revisar nuestra concepción de la ciencia que hemos heredado de las ciencias de la naturaleza, su modelo mecanicista, las abstracciones estadísticas, la concepción reduccionista de la causalidad, la idea de que no existe más que una solución posible...

La crisis parece haber sugerido que había otros derroteros posibles, por ejemplo lo que podríamos denominar la vuelta a una economía de las pasiones. Se percibe un deseo de recuperar una visión integral de la economía como una realidad antropológica y social, articulada con las ciencias humanas y sociales, que tome en consideración las pasiones humanas y las repercusiones sociales, más allá de los modelos abstractos al uso. El retorno a las pasiones en el vocabulario económico es una vuelta a los orígenes del pensamiento económico que, desde Adam Smith, situaba a la economía en un contexto antropológico. Forma parte de esta aproximación el intento de Amartya Sen de ampliar el alcance de la racionalidad económica a las «capacidades» criticando la idea del «idiota racional» propuesta por Arrow y que ha servido de fundamento a la teoría económica dominante, pero también otros muchos enfoques actuales muy similares, a los que aquí solo puedo referirme genéricamente (Akerlof y Shiller, 2009; Cohen, 2009; Latour y Lépinay, 2008; Sen, 1999).

No parece una casualidad que entre los economistas que menos se han equivocado a propósito de la crisis se encuentren aquellos que ejercen esta ciencia con un mayor aprecio hacia otras ciencias afines. Podríamos citar a muchos, pero yo subrayaría a Stiglitz o Akerlof, que han cuestionado la hipótesis neoclásica de que los participantes en el mercado disponen de una información perfecta y han llamado la atención sobre la importancia de considerar los fenómenos de psicología gregaria a 
la hora de explicar los fenómenos económicos. La crisis de la razón económica apela a la activación de otros modos de racionalización, donde se juegan también recursos simbólicos y cognitivos, fundamentalmente la gobernanza de los bienes sociales y las instituciones que estructuran el campo social.

La autonomización de la economía como disciplina académica es tributaria de una interpretación extremadamente ingenua del campo económico. No hay relaciones económicas sin instituciones, sin estados, sin regulaciones, sin lenguaje ni cultura. Es preciso que la economía vuelva a ser una ciencia social e histórica, que recupere su alianza con la filosofía social y política y no utilice la modelización matemática más que de manera accesoria e instrumental. Si los economistas más cercanos a la política o a la sociología se han equivocado menos con la crisis es, de entrada, por esta razón. Dado que la crisis económica se debe a una disociación entre lo económico y lo social, se requiere ahora un pensamiento económico que entienda la vinculación entre ambas dimensiones de la actividad humana.

La economía es una más entre las ciencias sociales y el largo periodo en el que se ha separado de ellas reivindicando su plena autonomía no ha sido satisfactorio ni para ella ni para el resto de las ciencias sociales. La complejidad creciente de los asuntos económicos justifica la especialización técnica, tanto en la economía como en cualquier otra ciencia, pero esto no se debe hacer al precio de perder de vista el lugar de la economía en el conjunto de los instrumentos de explicación de las realidades humanas, especialmente las relaciones entre la economía y la política. Es la hora de volver a quienes han considerado siempre la economía como una ciencia social y no como una ciencia exacta. Aplicar teorías al mundo real exige dominar un gran número de conocimientos sobre la política, la historia y el contexto local. Así lo entendieron Smith, Marx o Keynes, que tenían en común haber pensado la economía como un sistema de relaciones y no como una simple colección de mercados yuxtapuestos. Podríamos mencionar también la importancia que le otorgó a la sociología económica la rica tradición de Weber, Durkheim y Polanyi. La interdisciplinariedad o multidimensionalidad de las actividades económicas debería llevarla a practicar eso que Richard Bronk llama «eclecticismo disciplinado» (2009: 282). Tendría que solicitar la colaboración de todos los saberes, liberarse de las explicaciones unívocas y privilegiar las reflexiones fundadas sobre la interactividad, la incertidumbre y la complejidad. En definitiva, la economía debe salir de la economía si quiere comprender los fenómenos contemporáneos a los que nos enfrentamos.

Cómo contrasta el actual esoterismo económico con la sencillez de Alfred Marshall, que era por cierto también un gran matemático además de un gran economista, cuando recomendaba a uno de sus alumnos hacer todo lo posible para «impedir que la gente utilice las matemáticas cuando la lengua inglesa es tan concisa como la lengua matemática» (Marshall, 1996: 3, 130). 
Las llamadas a construir «otro mundo», el impulso que sostiene la crítica moral al capitalismo, son un signo de que el altermundialismo concede demasiada realidad al modelo que combate. Si hay que transitar hacia otro mundo, vienen a decir, es porque este ya no tiene remedio y su explicación está monopolizada por los «realistas». Ahora bien, no está nada claro que el «realismo» que pretende para sí la ciencia económica posea la consistencia que generalmente se le concede. Si algo le ha faltado a la economía - ahora podemos decirlo con una perspectiva acreditada por la historia reciente- es realismo.

Hay además un efecto perverso de esta crítica: la moral no basta para modificar la economía e incluso puede servir como contrapunto de la lógica mercantil. Los monopolizadores del realismo económico pueden sentirse bastante cómodos si quienes les critican no les plantan cara en el plano de la descripción de la realidad sino en el de los valores. La crítica al capitalismo contemporáneo, si quiere ser más radical que moralizante, debe dirigirse a combatir el supuesto realismo de la ciencia económica dominante.

No podemos continuar considerando, como afirmaba Popper, que solo nos cabe elegir entre la astronomía y la astrología, que no existe otra posibilidad que optar entre lo exacto y lo irracional. Hoy lo más revolucionario es una buena teoría... económica. La cuestión no es imaginar otro mundo sino elaborar otra economía para describir este y poder mejorarlo. No es otro mundo sino otra economía lo que necesitamos.

\section{Bibliografía}

Akerlof, George y Robert J. Shiller (2009): Animal Spirits: How Human Psycology Drives the Economy and Why it Matters for Global Capitalism, Princeton University Press.

Bronk, Richard (2009): The Romantic Economist. Imagination in Economics, Cambridge University Press, 282.

Cohen, Daniel (2009): La prospetité du vice. Une introduction (inquiète) à l'économie, París, Albin Michel.

Latour, Bruno y Vincent-Antonin LÉpinay (2008): L'Économie, science des intéréts passionés, Paris, La Découverte.

Marshald, Alfred (1996): The Correspondence of Alfred Marshall (ed. J. K. Whitaker), Cambridge University Press.

Sen, Amartya (1999), Development As Freedom, Nueva York, Knopf. 